\title{
Phase I/II study of S- I combined with irinotecan for metastatic advanced gastric cancer
}

\author{
M Inokuchi*,', T Yamashita ${ }^{2}$, H Yamada', K Kojima', W Ichikawa ${ }^{3}, Z$ Nihei ${ }^{4}$, T Kawano' and K Sugihara ${ }^{5}$ \\ 'Department of Esophagogastric Surgery, Tokyo Medical and Dental University, I-5-45, Yushima, Bunkyo, Tokyo II 3-85 I9, Japan; ${ }^{2}$ Mutsugi Clinic, I-4- \\ 14, Mutsugi, Adachi-ku, Tokyo 121 -0052, Japan; ${ }^{3}$ Department of Digestive and General Surgery, Saitama Medical School, 38, Moro-Hongo, Moroyama- \\ cho, Iruma-gun, Saitama 350-0495, Japan; ${ }^{4}$ Tojun Hospital 4-3-4, Hitotsuya, Adachi, Tokyo 121 -0075, Japan; ${ }^{5}$ Department of Surgical Oncology, Tokyo \\ Medical and Dental University, 1-5-45, Yushima, Bunkyo, Tokyo I I3-85 I9, Japan
}

A dose-escalation study of irinotecan (CPT-II) combined with $\mathrm{S}-\mathrm{I}$, an oral dihydropyrimidine dehydrogenase inhibitory fluoropyrimidine, was performed to determine the maximum-tolerated dose (MTD), recommended dose (RD), dose-limiting toxicities (DLTs), and objective response rate (RR) in advanced gastric cancer (AGC). S-I was administered orally at $80 \mathrm{mg} \mathrm{m}^{-2}$ day $^{-1}$ from day I to 14 of a 28-day cycle and CPT-II was given intravenously on day I and 8 at an initial dose of $70 \mathrm{mg} \mathrm{m}^{-2} \mathrm{day}^{-1}$, stepping up to $100 \mathrm{mg} \mathrm{m}^{-2}$. The treatment was repeated every 4 weeks, unless disease progression was observed In the phase I portion, the MTD of CPT-I I was presumed to be $100 \mathrm{mg} \mathrm{m}^{-2}$, because $66.6 \%$ of patients (two of three) developed DLTs. All three patients at the initial RD of CPT-I I $\left(90 \mathrm{mg} \mathrm{m}^{-2}\right)$ experienced grade 4 haematological or grade 3 nonhaematological toxicities at second course, followed by the dose reduction of CPT-I I from the third course. Considering safety and the ability to continue treatment, the final RD was determined to be $80 \mathrm{mg} \mathrm{m}^{-2}$. In the phase II portion, 42 patients including seven patients in the final RD phase I portion were evaluated. The median treatment course was five (range: I - 13). The incidences of severe (grade 3-4) haematological and nonhaematological toxicities were 19 and 10\%, respectively, but all were manageable. The RR was $62 \%$ (26 of 42 , 95\% confidence interval: 47.2-76.6\%), and the median survival time was 444 days. Our phase I/II trial showed S-I combined with CPT-II is effective for AGC and is well tolerated, with acceptable toxicity.

British Journal of Cancer (2006) 94, I | 30- | |35. doi:I0.1038/sj.bjc.6603072 www.bjcancer.com

Published online 28 March 2006

(c) 2006 Cancer Research UK

Keywords: S-I; irinotecan; combination chemotherapy; advanced gastric cancer

Unresectable advanced or recurrent gastric cancer still has a poor prognosis despite chemotherapy. Many randomised phase III studies of combination chemotherapy for unresectable advanced gastric cancer (AGC) resulted in median survival times (MSTs) of the 5-9.6 months and overall response rates (RRs) of $9-46 \%$ in Western and Asian countries (Webb et al, 1997; Icli et al, 1998; Vanhoefer et al, 2000; Ross et al, 2002; Ohtsu et al, 2003). The significant survival advantage of 5-fluorouracil (5-FU)-based chemotherapy for AGC has been demonstrated, compared with best supportive care (Murad et al, 1993; Pyrhonen et al, 1995; Glimelius et al, 1997); however, a standard regimen for AGC has not yet been established. New anticancer drugs, such as oral fluoropyrimidines, taxanes, and irinotecan hydrochloride (CPT11), have been developed and their antitumour effects against gastric cancer and good feasibility have been demonstrated (Futatsuki et al, 1994; Ajani et al, 1998; Sakata et al, 1998; Graziano et al, 2000; Koizumi et al, 2000).

$\mathrm{S}-1$ is an oral fluorinated pyrimidine that combines tegafur with two 5-FU-modulating substances, 5-chloro-2,4-dihydroxy pyridine

*Correspondence: Dr M Inokuchi;

E-mail: m-inokuchi.srg2@tmd.ac.jp

Received 16 December 2005; revised 13 February 2006; accepted 15 February 2006; published online 28 March 2006 and potassium oxonate, in a molar ratio of $1: 0.4: 1$ (Shirasaka et al, 1996). Tegafur is an oral prodrug of 5-FU, which is gradually converted to 5-FU. 5-chloro-2,4-dihydroxy pyridine is a reversible inhibitor of dihydropyrimidine dehydrogenase, which catabolises 5 -FU, leading to an increase in antitumour activity. Potassium oxonate is an orotate phosphoribosyltransferase inhibitor and decreases the incorporation of 5-FU triphosphate into RNA in the gastrointestinal mucosa. It reduces the incidence and severity of diarrhoea. According to the Japanese clinical trials of S-1, $80 \mathrm{mg} \mathrm{m}^{-2}$ day $^{-1}$ was the recommended dose (RD). In phase II trials of S-1 against unresectable or recurrent gastric cancer, RRs were $44-49 \%$ with a low incidence of severe toxicities (Sakata et al, 1998; Koizumi et al, 2000).

CPT-11 is an inhibitor of DNA topoisomerase I. A Japanese late phase II study of CPT-11 as a single agent for AGC obtained an RR of 23\% (Futatsuki et al, 1994). Some previous studies suggested a lack of crossresistance between CPT-11 with fluoropyrimidines (Houghton et al, 1996; Cao and Rustum, 2000). Combination of CPT-11 with 5-FU and leucovorin have shown promising activity not only in metastatic colorectal cancer but also in AGC (Douillard et al, 2000; Saltz et al, 2000; Assersohn et al 2004; Bouche et al, 2004; Pozzo et al, 2004).

We therefore conducted a phase I/II clinical study of combination treatment of S-1 with CPT-11. The primary objectives of the 
phase I study were to estimate the maximum-tolerated dose (MTD) of CPT-11 in combination with S-1 and to determine the RD for phase II studies. In the phase II study, we investigated the clinical activity and the feasibility of this chemotherapy regimen.

\section{PATIENTS AND METHODS}

\section{Patients}

Before entry, tumour size was determined by chest or gastrointestinal X-ray film, endoscopic examination of the upper gastrointestinal tract, computed tomographic (CT) scan of the abdomen, barium enema, and bone scintigram. Measurable lesions were selected according to response evaluation criteria in solid tumours (RECIST). A complete blood cell count, liver and renal function test, and urinalysis were performed within 7 days before entry. The eligibility criteria were as follows: age 20-80 years; histologically proven unresectable locally advanced or metastatic gastric adenocarcinoma; no previous chemotherapy or radiotherapy, adequate organ function, defined as haemoglobin $>8 \mathrm{~g} \mathrm{dl}^{-1}$, leucocyte count $>4000-12000 \mathrm{~mm}^{-3}$, platelet count $>100000 \mathrm{~mm}^{-3}$, serum bilirubin level $<1.5 \mathrm{mg} \mathrm{dl}^{-1}$, serum transaminase (aspartate aminotransferase and alanine aminotransferase) $<100 \mathrm{UI}^{-1}$, alkaline phosphatase $<$ twice the upper limit of the normal range (ULN), serum creatinine level less than the ULN; Eastern Cooperative Oncology performance status 0-1; expected survival period > 3 months; oral intake of medicines is possible; and written informed consent from the patients. Patients with symptomatic brain metastases, large ascites, or pleural effusion were not eligible. This study was approved by the ethics committees in each institution.

\section{Treatment schedule}

The fixed dose of S-1 (Taiho Pharmaceutical Co. Ltd, Tokyo, Japan) was $80 \mathrm{mg} \mathrm{m}^{-2}$ day $^{-1}$. Three doses of S-1 were established according to body surface area (BSA) as follows: BSA $<1.25 \mathrm{~m}^{2}$, $80 \mathrm{mg} \mathrm{day}^{-1}$; BSA $1.25-1.5 \mathrm{~m}^{2}, 100 \mathrm{mg} \mathrm{day}^{-1}$; and BSA $\geqslant 1.5 \mathrm{~m}^{2}$, $120 \mathrm{mg} \mathrm{day}^{-1}$, as described previously (Sakata et al, 1998; Koizumi et al, 2000). Patients received their assigned dose of S-1 divided in two, after breakfast and dinner orally. One course of therapy consisted of S-1 administered for 14 consecutive days. CPT-11 (Irinotecan; Daiichi Pharmaceutical Co. Ltd, Tokyo, Japan) was diluted in $500 \mathrm{ml}$ physiological saline, and administered as a $90 \mathrm{~min}$ intravenous (i.v.) infusion on days 1 and 8 . The starting dose of CPT-11 was $70 \mathrm{mg} \mathrm{m}^{-2}$ (level 1), which was to be increased in $10 \mathrm{mg} \mathrm{m}^{-2}$ increments to $100 \mathrm{mg} \mathrm{m}^{-2}$ (level 4), unless the MTD were achieved. No intrapatient dose escalation was allowed. At least three patients were treated at each dose level. If one of three patients at a given dose developed any dose-limiting toxicity (DLT), three or more patients were entered at the same dose. Before proceeding to the next dose level, all patients had received at least one course. This treatment course was repeated every 4 weeks with an allowance for a delay in treatment if toxicity was observed. The next course was started only for patients whose biological parameters had been maintained at levels satisfying the eligibility criteria, except for the leucocyte count $\left(>3000 \mathrm{~mm}^{-3}\right)$, and with no disease progression observed. Prophylactic administration of antiemetic medication $\left(5-\mathrm{HT}_{3}\right.$ antagonist and corticosteroid) at standard doses was routinely used when CPT-11 was administered to prevent nausea and vomiting. The treatment was repeated unless disease progression or severe toxicity was observed.

\section{Evaluation}

A complete blood cell count, liver and renal function test, and urinalysis were assessed at least once a week during the first course, and every other week afterwards. Before each course, additional examinations were performed to evaluate sites. The National Cancer Institute common toxicity criteria version 2.0 was applied to evaluate the toxicity of this therapy during each course. Dose-limiting toxicities were defined as grade 4 neutropenia, grade 4 thrombocytopenia, any febrile grade 3 or 4 haematological toxicity, or grade 3 nonhaematological toxicity (except nausea and vomiting) during the first course. The MTD was defined as the dose at which $>33 \%$ patients experienced DLTs during the first course. Lesions noted at baseline and 1 week after each course were measured or evaluated by CT. Objective responses were evaluated according to the RECIST criteria. The survival period was calculated from the start of treatment to death or the latest followed-up day. The eligibility and suitability for assessment and the objective response to the treatment were reviewed extramurally.

\section{RESULT}

Between January 2001 and December 2003, 51 eligible patients were entered in this study. The first 16 patients were entered into the phase I portion and the next 35 patients were entered into the phase II portion to confirm the toxicities and efficacy at the RD. All patients were eligible for toxicity evaluation in any course and objective response evaluations (Table 1). Thirty-one patients had undergone gastrectomy and none had received adjuvant chemotherapy after gastrectomy. Histological evaluation revealed 21 patients to be intestinal type and 30 patients to be diffuse type. A total of 267 courses were given. The median number of treatment courses was four (range: 1-16) and five (range: 1-13) in phase I and II portion, respectively (Table 2). The median duration of therapy per patient was 161 days (range: 28-637) in phase I portion, and 172 days (range: 28-599) in phase II portion, respectively. The median number of days until the start of the second course after completion of scheduled S-1 in the first course was 14 (range: 14-21 days) among 46 patients who were treated with two courses or more. Three of the six patients at level 3 and 4 required more than 14 days interval to start the second course, although none of 42 patients did in phase II portion.

Table I Patient characteristics

\begin{tabular}{|c|c|c|c|c|c|}
\hline \multirow[b]{2}{*}{ Level } & \multicolumn{4}{|c|}{ Phase I portion } & \multirow{2}{*}{ Phase II portion } \\
\hline & $\mathbf{I}$ & 2 & 3 & 4 & \\
\hline CPT-II $\left(\mathrm{mg} \mathrm{m}^{-2}\right)$ & 70 & 80 & 90 & 100 & 80 \\
\hline No. of patients & 3 & 7 & 3 & 3 & 35 \\
\hline \multicolumn{6}{|l|}{ Age (years) } \\
\hline Median & 70 & 57 & 58 & 63 & 63 \\
\hline Range & $68-76$ & $39-73$ & $5 \mathrm{I}-77$ & $21-67$ & $47-79$ \\
\hline$<65$ & 0 & 5 & 2 & 2 & 18 \\
\hline$\geqslant 65$ & 3 & 2 & 1 & I & 17 \\
\hline \multicolumn{6}{|l|}{ Sex } \\
\hline Female & 0 & I & 0 & I & 13 \\
\hline Male & 3 & 6 & 3 & 2 & 22 \\
\hline \multicolumn{6}{|l|}{ Pathology } \\
\hline Intestinal & 2 & 2 & I & 0 & 16 \\
\hline Diffuse & I & 5 & 2 & 3 & 19 \\
\hline Gastrectomy & । & 5 & 2 & 2 & 21 \\
\hline
\end{tabular}




\section{Determination of MTD}

In the phase I portion at level 2, one patient developed grade 3 diarrhoea during the first course, but the other two patients in the same cohort showed no DLT. An additional four patients were enrolled for safety evaluation, but overall only one of the total of seven patients developed a DLT at $80 \mathrm{mg} \mathrm{m}^{-2}$ of CPT-11. As dose level 4, two of three patients exhibited DLTs in the first course, one of whom had grade 3 febrile leucopenia and neutropenia, and grade 4 thrombocytopenia, another had grade 3 nonhaematological toxicity (diarrhoea). The frequency of severe haematological and nonhaematological toxicities increased according to the increment of the CPT-11 dose (Table 3). Based on these results, dose level 4 was declared as the MTD, and level 3 should be declared as the initial RD according to the protocol. However, all three patients at level 3 experienced grade 4 haematological or grade 3 nonhaematological toxicities during the second course, followed by dose reduction of CPT-11 from the third course. The dose intensity per course of CPT- 11 was $86 \%$ of planned CPT- 11 dose at level 3, compared with $96 \%$ at level 2 (Table 2). Thus, considering the safety and the continuation of the treatment, the final RD was level 2 dose of $80 \mathrm{mg} \mathrm{m}^{-2}$ in the following phase II portion.

Table 2 Completed course and dose intensity (DI)

\begin{tabular}{|c|c|c|c|c|c|}
\hline \multirow[b]{2}{*}{ Level } & \multicolumn{4}{|c|}{ Phase I portion } & \multirow{3}{*}{ Phase II portion ${ }^{\mathrm{a}}$} \\
\hline & $\mathbf{I}$ & 2 & 3 & 4 & \\
\hline CPT-II $\left(\mathrm{mg} \mathrm{m}^{-2}\right)$ & 70 & 80 & 90 & 100 & \\
\hline$n$ & 3 & 7 & 3 & 3 & 42 \\
\hline \multicolumn{6}{|l|}{ Course } \\
\hline Median & 9 & 4 & 6 & 3 & 5 \\
\hline Range & $6-16$ & $1-13$ & $3-7$ & $2-4$ & $1-13$ \\
\hline \multicolumn{6}{|l|}{$S-1$} \\
\hline $\mathrm{DI}$ & 1120 & 1120 & 1120 & 1089 & 1099 \\
\hline$\% \mathrm{DI}$ & 100 & 100 & 100 & 97 & 98 \\
\hline \multicolumn{6}{|l|}{ CPT-II } \\
\hline $\mathrm{Dl}$ & 140 & 155 & 155 & 169 & $15 \mid$ \\
\hline \%Dl & 100 & 96 & 86 & 84 & 94 \\
\hline
\end{tabular}

$\mathrm{DI}=$ dose $\left(\right.$ per $\left.\mathrm{m}^{2}\right)$ per course. ${ }^{\mathrm{a}}$ Including seven patients at level 2 of phase I portion.

\section{Safety}

In the 42 patients of the phase II portion including seven patients assigned at level 2 in the phase I portion, the most frequently observed severe (grades 3 and 4) haematological toxicity was neutropenia (6 cases, 14\%) (Table 3). Frequently observed nonhaematological toxicities (all events) included nausea (25 cases, 59\%), anorexia (23 cases, 55\%), and vomiting (16 cases, $38 \%$ ). In addition, the overall incidence of diarrhoea was $40 \%$ (17 out of 42); however, grade 3 or 4 diarrhoea was observed in four out of $42(10 \%)$, and recovered within seven days (Table 3). During this study, eight patients received granulocyte colony-stimulating factor because of neutropenia. Incidences of the worst-grade toxicities in patients treated with the final RD were none (four cases, $10 \%$ ), grade 1 (11 cases, $26 \%$ ), grade 2 (16 cases, $38 \%$ ), grade 3 (seven cases, $17 \%$ ), and grade 4 (four cases, $10 \%$ ), respectively. Neither treatment-related death nor delayed severe toxicity was observed.

\section{Efficacy}

All 42 patients including seven patients assigned in phase I portion were evaluated to determine the RR at the RD. The RR at the RD in the phase II portion was $62 \%$ ( 26 of $42,95 \%$ confidence interval (CI): $47.2-76.6 \%$ ); 11 patients showed stable disease as their best response, five patients had PD (Table 4). The median time to progression (TTP) was 195 days (range: 25-684) in the phase II portion (Figure 1). The median time to response and the median overall durations of response in 26 responders in phase II portion were 48 (range: 28-158) and 178 days (range: 66-643),

Table 4 Response rate

\begin{tabular}{lcccccc}
\hline & n & CR & PR & SD & PD & Response (\%) \\
\hline Phase II portion & 42 & 0 & 26 & 11 & 5 & 62 \\
$\quad$ Lymph nodes & 25 & 0 & 15 & 8 & 2 & 60 \\
Liver & 12 & 0 & 7 & 3 & 2 & 58 \\
Peritoneum & 13 & 0 & 9 & 2 & 2 & 69 \\
Primary & 16 & 0 & 11 & 3 & 2 & 69 \\
Total & 51 & 1 & 30 & 15 & 5 & 61 \\
\hline
\end{tabular}

$\mathrm{CR}=$ complete response; $\mathrm{PR}=$ partial response; $\mathrm{SD}=$ stable disease; $\mathrm{PD}=$ progressive disease. Response rate $=$ number of $\mathrm{CR}$ and PR/total number (n).

Table 3 Toxicity incidence

\begin{tabular}{|c|c|c|c|c|c|c|c|c|c|c|}
\hline \multirow{3}{*}{$\begin{array}{l}\text { Course } \\
\text { CPT-II }\left(\mathrm{mg} \mathrm{m}^{-2}\right) \\
\text { No.of patients } \\
\text { Toxicity/grade }\end{array}$} & \multicolumn{8}{|c|}{$\begin{array}{l}\text { Phase I portion } \\
\text { First course }\end{array}$} & \multirow{2}{*}{\multicolumn{2}{|c|}{$\begin{array}{l}\text { Phase II portion } \\
\text { All courses } \\
\\
80 \\
42\end{array}$}} \\
\hline & \multicolumn{2}{|c|}{$\begin{array}{c}70 \\
3\end{array}$} & \multicolumn{2}{|c|}{$\begin{array}{c}80 \\
7\end{array}$} & \multicolumn{2}{|c|}{$\begin{array}{c}90 \\
3\end{array}$} & \multicolumn{2}{|c|}{$\begin{array}{c}100 \\
3\end{array}$} & & \\
\hline & All events & Grade 3/4 & All events & Grade $3 / 4$ & All events & Grade $3 / 4$ & All events & Grade 3/4 & All events & Grade $3 / 4$ \\
\hline Anaemia & 1 & 0 & 0 & 0 & 2 & 0 & 2 & 1 & 20 & 3 \\
\hline Thrombocytopenia & 0 & 0 & 0 & 0 & 0 & 0 & । & i & 5 & 2 \\
\hline \multicolumn{11}{|l|}{ Nonhaematological } \\
\hline Anorexia & 3 & 0 & 3 & 0 & 2 & 0 & 2 & I & 23 & 4 \\
\hline Nausea & 3 & 0 & 4 & 0 & 2 & 0 & 2 & 1 & 25 & 3 \\
\hline
\end{tabular}

Including seven patients at level 2 of phase I portion. 


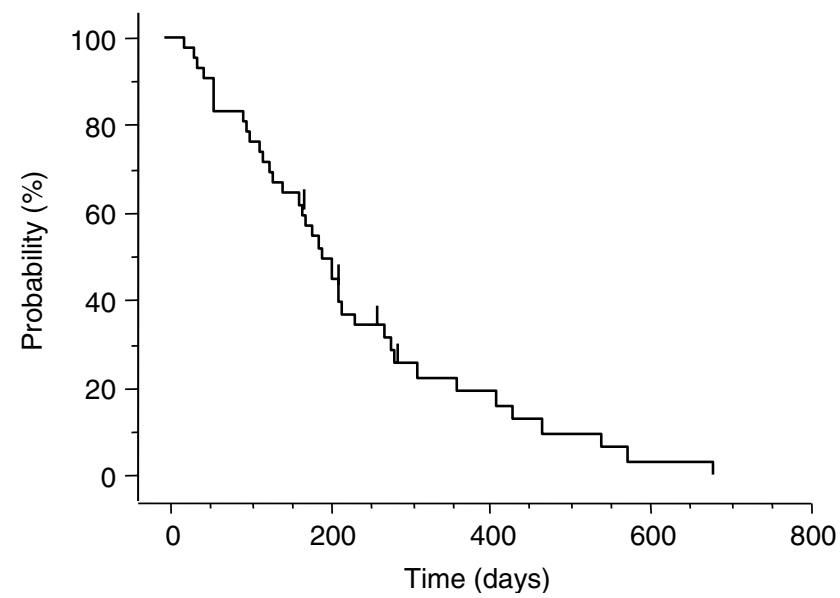

Figure I Time to progression curve for the 42 patients in the phase I| portion; the median TTP was 195 days (range: 25-684 days).

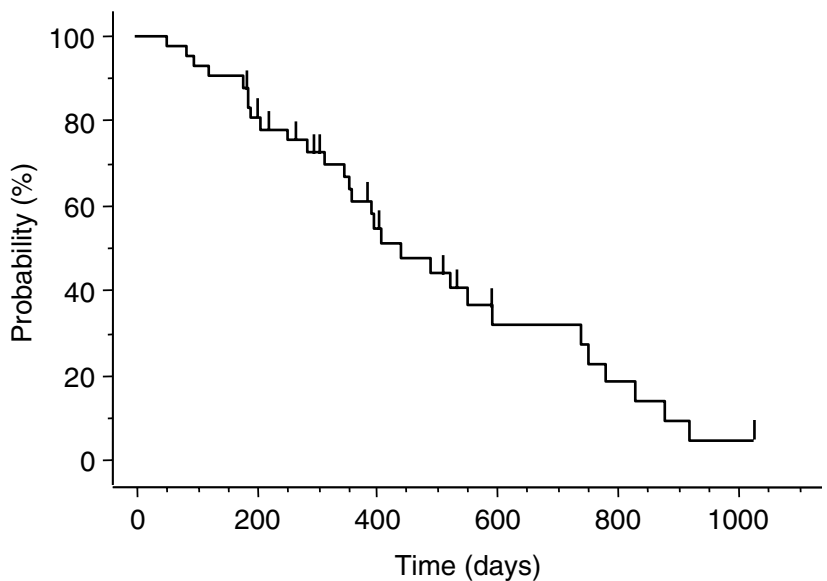

Figure 2 Cumulative overall survival for the 42 patients in the phase II portion. The median survival time was 444 days (range: 54- 1029 days).

respectively. One patient was able to undergo gastrectomy after five courses of combination therapy. Subgroup analysis according to tumour lesion and pathological type for the 42 patients in phase II portion showed that the RR was $58 \%$ (seven of 12) for liver metastasis, $60 \%$ (15 of 25 ) for lymph node metastasis, $69 \%$ (nine of 13) for metastatic peritoneal nodule, and 69\% (11 of 16) for primary lesions (Table 4), and the RR according to pathological type was $61 \%$ ( 11 of 18 ) for the intestinal type and 63\% (15 of 24) for the diffuse type. The MST of patients in the phase II portion was 444 days (range: 54-1029) and 1- and 2-year survival rates were 61 and $28 \%$, respectively (Figure 2). The median follow-up time for survival analysis was 736 days.

\section{DISCUSSION}

This study was undertaken to determine the RD for a phase II study of CPT-11 combined with S-1 for metastatic advanced gastric cancer and to investigate the antitumour effect and feasibility of this combination. The $\mathrm{RD}$ was determined to be $80 \mathrm{mg} \mathrm{m}^{-2}$ of CPT-11 on day 1 and day 8 , and $80 \mathrm{mg} \mathrm{m}^{-2}$ per day of S-1 on days $1-14$ of a 28 -day cycle. The phase II study using this combination obtained an RR of $62 \%$ ( 26 of 42 ), and in particular, the MST of
444 days and the TTP of 195 days for chemotherapy-naïve patients were promising. In addition, toxicity was mild and tolerable, and therapy was administrated on an outpatient basis.

Two late phase II studies of S-1 as a single agent in advanced gastric cancer in Japan obtained RRs of 44 and 49\%, respectively (Sakata et al, 1998; Koizumi et al, 2000). Combined analysis of the results of these phase II studies suggested an MST of 244 days, while toxicities were generally mild. Based on these data, there are several ongoing combination studies of S-1 with another anticancer agent with a different mechanism of action, aimed at achieving more survival benefit.

CPT-11 was shown to lack crossresistance with fluoropyrimidines in both experimental and clinical settings (Vanhoefer et al, 2001). The response rate of CPT-11 alone in gastric cancer was $23 \%$ in a Japanese phase II study (Futatsuki et al, 1994). The response rate in patients with previous 5 -FU-containing regimens was $18.9 \%$, which indicated a lack of crossresistance between CPT-11 and 5-FU in gastric cancer. Preclinical studies of human cancer cell lines and tumour xenografts have suggested that the combination of CPT-11 and 5-FU has additive-to-synergistic antitumour activities (Houghton et al, 1996). Thus, we selected CPT-11 as the combination agent to be used with S-1.

When CPT-11 is combined with S-1, there is concern about the increase of the frequency of severe diarrhoea, which is the common toxicity not only in CPT-11 alone regimen but also in S-1 alone regimen. As the median time to deteriorate into the worst grade of S-1-induced diarrhoea was 15 days of consecutive S-1alone administration (Nagashima et al, 2005), we planned that CPT-11 was administrated i.v. on day 1 and day 8, and S-1 was orally taken for 2 consecutive weeks followed by 2 -week drug holiday. In this phase I portion, S-1 was given at a fixed dose of $80 \mathrm{mg} \mathrm{m}^{-2}$ day $^{-1}$ and the CPT-11 dose was escalated from $70 \mathrm{mg} \mathrm{m}^{-2}$ as level 1 to $100 \mathrm{mg} \mathrm{m}^{-2}$ as level 4 . DLTs were observed in two of three patients at level 4 , which was defined as the MTD. DLTs consisted of grade 3 febrile neutropenia, grade 4 thrombocytopenia, and grade 3 diarrhoea. According to the protocol conditions, the initial RD of CPT-11 combined with S-1 should be the level 3 dose of $90 \mathrm{mg} \mathrm{m}^{-2}$; however, all three patients assigned the level 3 dose experienced grade 4 haematological or grade 3 nonhaematological toxicities in the second course. Considering the safety and the ability to continue treatment, the final RD of CPT-11 was the level 2 dose of $80 \mathrm{mg} \mathrm{m}^{-2}$. In the phase II portion, the incidence of the most common toxicities (grade 3 or 4 ) was $14 \%$ for neutropenia, and $10 \%$ for diarrhoea and anorexia. Thus, mild and tolerable toxicities resulted in the median treatment course of 5 , achieving an RR of 62 and MST of 444 days.

Three other phase I studies for combination therapy with CPT-11 and S-1 have been reported. Yamada et al (2003) reported an RD of $150 \mathrm{mg} \mathrm{m}^{-2}$ CPT-11 administration on day 1 with $80 \mathrm{mg} \mathrm{m}^{-2}$ day $^{-1} \mathrm{~S}-1$ administration from day 1 to day 14 of a 21day cycle. Another study assigned patients to receive $80 \mathrm{mg} \mathrm{m}^{-2}$ CPT- 11 on days 1 and 15, and S-1 from day 1 to day 21, followed by a 2 -week rest (Takiuchi et al, 2005). In the two regimens, the doses of S-1 were similar to single-agent therapy of S-1, which consist of 4-week consecutive administration with a 2-week rest. On the other hand, Komatsu et al (2005) reported the regimen of $125 \mathrm{mg} \mathrm{m}^{-2}$ CPT-11 on day 1 and day 15, combined with $80 \mathrm{mg} \mathrm{m}^{-2}$ day $^{-1} \mathrm{~S}-1$ administration from day 1 to day 14 of a 28 day cycle. The dose intensity of S-1 in that regimen, as in ours, is smaller than that of the single-agent S-1 therapy. Little constructive information can be obtained by comparing the results of these different studies. However, we are the first to report the promising result of the phase II portion for combination therapy with CPT-11 and S-1, in detail.

Previous reports indicated that 5-FU might inhibit the conversion of CPT-11 to SN-38, which is its active form (Sasaki et al, 1994; Falcone et al, 2001). On the contrary, it has been reported that pharmacokinetic (PK) analysis of CPT-11 when combined 
with S-1 showed no change in any PK parameter as compared with the expected values for CPT-11 as a single agent (Yamada et al, 2003). Additionally, the PK results of S-1 combined with CPT-11 were similar to those obtained by S-1 single-agent treatment (Takiuchi et al, 2005). Taken together with these data, it appears there is no PK interaction between CPT-11 and S-1.

Cisplatin has been employed in the treatment of AGC. Boku et al (1999) reported the promising results of $48 \%$ RR and 322 days MST for AGC treated by CPT-11 combined with CDDP, with acceptable toxicity. A phase I/II study of S-1 combined with CDDP indicated the surprising results of an RR of 74\% (Koizumi et al, 2003). However, the MST of S-1 combined with CDDP was 383 days, which was shorter than the 444 days in our study. The incidence of grade 3 or 4 haematological toxicities was almost the same (16 and 19\% in the CDDP combination and CPT-11 combination, respectively), whereas the incidence of nonhaematological toxicities was $26 \%$ in S-1 combined with CDDP, which was higher than the $10 \%$ in our study. Additionally, in the combination of CDDP, it is necessary to hydrate patients with drip infusion to avoid of CDDP-induced renal damages. Thus, S-1 combined with CPT-11 might be less toxic and more easily manageable in outpatient clinics than the CDDP-combined regimens.

In three randomised phase II trials, the combination of CPT-11 and 5-FU/LV was compared with the combination of CPT-11 and CDDP (Pozzo et al, 2004), CDDP and 5-FU/LV (Bouche et al, 2004), and etoposide and 5-FU/LV (ELF) (Moehler et al, 2005). All

\section{REFERENCES}

Ajani JA, Fairweather J, Dumas P, Patt YZ, Pazdur R, Mansfield PF (1998) Phase II study of Taxol in patients with advanced gastric carcinoma. Cancer J Sci Am 4: 269-274

Assersohn L, Brown G, Cunningham D, Ward C, Oates J, Waters JS, Hill ME, Norman AR (2004) Phase II study of irinotecan and 5-fluorouracil/ leucovorin in patients with primary refractory or relapsed advanced oesophageal and gastric carcinoma. Ann Oncol 15: 64-69

Boku N, Ohtsu A, Shimada Y, Shirao K, Seki S, Saito H, Sakata Y, Hyodo I (1999) Phase II study of a combination of irinotecan and cisplatin against metastatic gastric cancer. J Clin Oncol 17: 319-323

Bouche O, Raoul JL, Bonnetain F, Giovannini M, Etienne PL, Lledo G, Arsene D, Paitel JF, Guerin-Meyer V, Mitry E, Buecher B, Kaminsky MC, Seitz JF, Rougier P, Bedenne L, Milan C (2004) Randomized multicenter phase II trial of a biweekly regimen of fluorouracil and leucovorin (LV5FU2), LV5FU2 plus cisplatin, or LV5FU2 plus irinotecan in patients with previously untreated metastatic gastric cancer: a Federation Francophone de Cancerologie Digestive Group Study - FFCD 9803. J Clin Oncol 22: 4319-4328

Cao S, Rustum YM (2000) Synergistic antitumour activity of irinotecan in combination with 5-fluorouracil in rats bearing advanced colorectal cancer: role of drug sequence and dose. Cancer Res 60: 3717-3721

Dank M, Zaluski J, Barone C, Valvere V, Peschel C, Wenczl M, Goker E, Risse M, Awad L, Bugat R (2005) Randomized phase 3 trial of irinotecan $(\mathrm{CPT}-11)+5 \mathrm{FU} /$ folinic acid (FA) vs CDDP+5FU in 1 st-line advanced gastric cancer patients. Proc Am Soc Clin Oncol 23: 4003

Douillard JY, Cunningham D, Roth AD, Navarro M, James RD, Karasek P, Jandik P, Iveson T, Carmichael J, Alakl M, Gruia G, Awad L, Rougier P (2000) Irinotecan combined with fluorouracil compared with fluorouracil alone as first-line treatment for metastatic colorectal cancer: a multicentre randomised trial. Lancet 355: $1041-1047$

Falcone A, Di Paolo A, Masi G, Allegrini G, Danesi R, Lencioni M, Pfanner E, Comis S, Del Tacca M, Conte P (2001) Sequence effect of irinotecan and fluorouracil treatment on pharmacokinetics and toxicity in chemotherapy-naive metastatic colorectal cancer patients. J Clin Oncol 22: $3456-3462$

Futatsuki K, Wakui A, Nakao I, Sakata Y, Kambe M, Shimada Y, Yoshino M, Taguchi T, Ogawa N (1994) Late phase II study of irinotecan hydrochloride (CPT-11) in advanced gastric cancer. CPT-11 Gastrointestinal Cancer Study Group. Jpn J Cancer Chemother 21: 1033-1038

Glimelius B, Ekström K, Hoffman K, Graf W, Sjoden PO, Haglund U, Svensson C, Enander LK, Linne T, Sellstrom H, Heuman R (1997) three trials indicated that the combination of CPT-11 and 5-FU/LV was the most effective combination and will be assessed in a phase III trails. The RR, TTP, and MST in the combination arm of CPT11 and 5-FU/LV ranged from 30 to $40 \%, 4.5-6.9$ months, and $10.8-11.3$ months, respectively, with acceptable toxicity profiles. In addition, the randomised phase III study confirmed that the combination of CPT-11 and 5-FU/LV is superior in terms of TTP, compared with the combination of CPT-11 and CDDP (Dank et al, 2005). These results underline the potential role of the combination of CPT-11 and 5-FU/LV. If S-1 could be used instead of 5-FU infusion, S-1 combined with CPT-11 might become an alternative to the combination of CPT-11 and 5-FU/LV. We are awaiting the results of a randomised phase III trial (5-FU infusion $v s \mathrm{~S}-1$ vs CPT-1 with CDDP) for AGC patients.

In conclusion, our phase I/II trial showed S-1 combined with CPT-11 is effective and well tolerated with acceptable toxicity. This regimen should be one of the choices for an experimental arm in phase III trials in near future.

\section{ACKNOWLEDGEMENTS}

We are indebted to Professor J Patrick Barron of the International Medical Communications Center of Tokyo Medical University for his review of this paper.
Randomized comparison between chemotherapy plus best supportive care with best supportive care in advanced gastric cancer. Ann Oncol 8: $163-168$

Graziano F, Catalano V, Baldelli AM, Giordani P, Testa E, Lai V, Catalano G, Battelli N, Cascinu S (2000) A phase II study of weekly docetaxel as salvage chemotherapy for advanced gastric cancer. Ann Oncol 11: 1263 1266

Houghton JA, Cheshire PJ, Hallman II JD, Lutz L, Luo X, Li Y, Houghton PJ (1996) Evaluation of irinotecan in combination with 5-fluorouracil or etoposide in xenograft models of colon adenocarcinoma and rhabdomyosarcoma. Clin Cancer Res 2: 107-118

Icli F, Celik I, Aykan F, Uner A, Demirkazik A, Ozet A, Ozguroglu M, Tas F, Akbulut H, Firat D (1998) A randomized phase III trial of etoposide, epirubicin, and cisplatin $v s$ 5-fluorouracil, epirubicin, and cisplatin in the treatment of patients with advanced gastric carcinoma. Turkish Oncology Group. Cancer 83: 2475-2480

Koizumi W, Kurihara M, Nakano S, Hasegawa K (2000) Phase II study of S-1, a novel oral derivative of 5-fluorouracil, in advanced gastric cancer. For the S-1 Cooperative Gastric Cancer Study Group. Oncology 58: $191-197$

Koizumi W, Tanabe S, Saigenji K, Ohtsu A, Boku N, Nagashima F, Shirao K, Matsumura Y, Gotoh M (2003) Phase I/II study of S-1 combined with cisplatin in patients with advanced gastric cancer. Br J Cancer 89: $2207-2212$

Komatsu Y, Yuuki S, Fuse N, Takei M, Kato T, Miyagishima T, Kudo M, Kunieda Y, Tateyama M, Wakahama O, Meguro T, Ohizumi $\mathrm{H}$, Watanabe M, Akita H, Sakata Y, Asaka M (2005) Phase II study of oral S-1 plus irinotecan in patients with advanced colorectal cancer: Hokkaido Gastrointestinal Cancer Study Group HGCSG0302. Jpn J Clin Oncol 35: 88-89

Moehler M, Eimermacher A, Siebler J, Hohler T, Wein A, Menges M, Flieger D, Junginger T, Geer T, Gracien E, Galle PR, Heike M (2005) Randomised phase II evaluation of irinotecan plus high-dose 5-fluorouracil and leucovorin (ILF) vs 5-fluorouracil, leucovorin, and etoposide (ELF) in untreated metastatic gastric cancer. Br J Cancer 92: 2122-2128

Murad AM, Santiago FF, Petroianu A, Rocha PR, Rodrigues MA, Rausch M (1993) Modified therapy with 5-fluorouracil, doxorubicin, and methotrexate in advanced gastric cancer. Cancer 72: 37-41

Nagashima F, Ohtsu A, Yoshida S, Ito K (2005) Japanese nationwide postmarketing survey of S-1 in patients with advanced gastric cancer. Gastric Cancer 8: 6-11 
Ohtsu A, Shimada Y, Shirao K, Boku N, Hyodo I, Saito H, Yamamichi N, Miyata Y, Ikeda N, Yamamoto S, Fukuda H, Yoshida S (2003) Randomized phase III trial of fluorouracil alone $v s$ fluorouracil plus cisplatin $v s$ uracil and tegafur plus mitomycin in patients with unresectable, advanced gastric cancer: The Japan Clinical Oncology Group Study (JCOG9205). J Clin Oncol 21: 54-59

Pozzo C, Barone C, Szanto J, Padi E, Peschel C, Bukki J, Gorbunova V, Valvere V, Zaluski J, Biakhov M, Zuber E, Jacques C, Bugat R (2004) Irinotecan in combination with 5-fluorouracil and folinic acid or with cisplatin in patients with advanced gastric or esophageal-gastric junction adenocarcinoma: results of a randomized phase II study. Ann Oncol 15: $1773-1781$

Pyrhonen S, Kuitunen T, Nyandoto P, Kouri M (1995) Randomised comparison of fluorouracil, epidoxorubicin and methotrexate (FEMTX) plus supportive care with supportive care alone in patients with nonresectable gastric cancer. $\mathrm{Br} J$ Cancer 71: 587-591

Ross P, Nicolson M, Cunningham D, Valle J, Seymour M, Harper P, Price T, Anderson H, Iveson T, Hickish T, Lofts F, Norman A (2002) Prospective randomized trial comparing mitomycin, cisplatin, and protracted venous-infusion fluorouracil (PVI 5-FU) With epirubicin, cisplatin, and PVI 5-FU in advanced esophagogastric cancer. I Clin Oncol 20: $1996-2004$

Sakata Y, Ohtsu A, Horikoshi N, Sugimachi K, Mitachi Y, Taguchi T (1998) Late phase II study of novel oral fluoropyrimidine anticancer drug S-1 (1 Mtegafur-0.4 Mgimestat-1 Motastat potassium) in advanced gastric cancer patients. Eur J Cancer 34: 1715-1721

Saltz LB, Cox JV, Blanke C, Rosen LS, Fehrenbacher L, Moore MJ, Maroun JA, Ackland SP, Locker PK, Pirotta N, Elfring GL, Miller LL (2000) Irinotecan plus fluorouracil and leucovorin for metastatic colorectal cancer. Irinotecan Study Group. N Engl J Med 13: 905-914

Sasaki Y, Ohtsu A, Shimada Y, Ono K, Saijo N (1994) Simultaneous administration of CPT-11 and fluorouracil: alteration of the pharmaco- kinetics of CPT-11 and SN-38 in patients with advanced colorectal cancer. J Natl Cancer Inst 86: 1096-1098

Shirasaka T, Shimamoto Y, Ohshimo H, Yamaguchi M, Kato T, Yonekura K, Fukushima M (1996) Development of a novel form of an oral 5 -fluorouracil derivative (S-1) directed to the potentiation of the tumour selective cytotoxicity of 5 -fluorouracil by two biochemical modulators. Anticancer Drugs 7: 548-557

Takiuchi H, Narahara H, Tsujinaka T, Gotoh M, Kawabe S, Katsu K, Iishi H, Tatsuta M, Fujitani K, Furukawa H, Taguchi T (2005) Phase I study of S-1 combined with irinotecan (CPT-11) in patients with advanced gastric cancer (OGSG 0002). Jpn J Clin Oncol 35: 520-525

Vanhoefer U, Harstrick A, Achterrath W, Cao S, Seeber S, Rustum YM (2001) Irinotecan in the treatment of colorectal cancer: clinical overview. J Clin Oncol 19: $1501-1518$

Vanhoefer U, Rougier P, Wilke H, Ducreux MP, Lacave AJ, Van Cutsem E, Planker M, Santos JG, Piedbois P, Paillot B, Bodenstein H, Schmoll HJ, Bleiberg H, Nordlinger B, Couvreur ML, Baron B, Wils JA (2000) Final results of a randomized phase III trial of sequential high-dose methotrexate, fluorouracil, and doxorubicin $v s$ etoposide, leucovorin, and fluorouracil $v s$ infusional fluorouracil and cisplatin in advanced gastric cancer: a trial of the European Organization for Research and Treatment of Cancer of the Gastrointestinal Tract. J Clin Oncol 18: 2648-2657

Yamada Y, Yasui H, Goto A, Arai T, Ura T, Hamaguchi T, Muro K, Shimada Y, Shirao K (2003) Phase I study of irinotecan and S-1 combination therapy in patients with metastatic gastric cancer. Int J Clin Oncol 8: $374-380$

Webb A, Cunningham D, Scarffe JH, Harper P, Norman A, Joffe JK, Hughes M, Mansi J, Findley M, Hill A, Oates J, Nicolson M, Hickish T, O'Brien M, Iveson T, Watson M, Underhill C, Wardley A, Meehan M (1997) Randomized trial comparing epirubicin, cisplatin, and fluorouracil $v s$ fluorouracil, doxorubicin, and methotrexate in advanced esophagogastric cancer. J Clin Oncol 15: 261-267 